\title{
Comparative study of thermophilic and mesophilic anaerobic treatment of purified terephthalic acid (PTA) wastewater
}

\author{
Michael Olawale Daramola ${ }^{1 *}$, Elizabeth Funmilayo Aransiola ${ }^{1}$, Adeniyi Ganiyu Adeogun $^{2}$ \\ ${ }^{1}$ Department of Chemical Engineering, Obafemi Awolowo University, Ile-Ife, Nigeria; ${ }^{*}$ Corresponding Author: \\ kennydara@yahoo.com \\ ${ }^{2}$ Department of Integrated Urban Engineering, UNESCO-IHE Institute of Water Education, Delft, The Netherlands.
}

Received 11 February 2011; revised 5 March 2011; accepted 27 March 2011.

\begin{abstract}
The paper provides a critical comparison between mesophilic and thermophilic anaerobic treatment of PTA wastewater through diagnosis of a case study. Aspects covered are bioavailability, biodegradability, microbial population, thermodynamics, kinetics involved and bioreactor design for PTA wastewater treatment. The results of the case study suggests that onestage thermophilic anaerobic reactor coupled with coagulation-flocculation pre-treatment unit and an aerobic post treatment unit could be techno-economically viable for PTA wastewater treatment to ensure that the final effluent quality conforms to the international standard. The information emanated from this study could be useful and thought provoking to the professionals and academia in the area of PTA wastewater treatment and can serve as impetus toward the development of research lines in similar problems like the treatment of other petrochemical wastewater such as phenol-containing wastewater, benzene/benzoic acid-containing wastewater or wastewater from other similar industrial settings.
\end{abstract}

Keywords: Terephthalic Acid; Wastewater Treatment; Anaerobic and Aerobic Treatment; Mesophilic and Thermophilic Conditions; Bioreactors

\section{INTRODUCTION}

In 1997, worldwide production of purified terephthalic acid (PTA) was 18.22 million tons and it grew steadily to about 26.12 million tons in 2002 at an annual growth rate of $7.5 \%$ with China growth rate accounted for about
2.6 million tons. In 2005, the demand for PTA in China rose up to 12.14 million tons contributing to $42 \%$ of the total world demand of about 28.8 million tones [1,2].

The process for the production of PTA developed by the American Amoco Group [3] comprises:

- Wet oxidation of $p$-Xylene into acetic acid to produce crude terephthalic acid (CTA).

- Hydrogenation of CTA into PTA over palladium as a catalyst [4].

During the process, about $4-10 \mathrm{~kg} C O D \cdot \mathrm{m}^{-3}$ are generated with $5-20 \mathrm{COD} \cdot \mathrm{L}^{-1}$, and $3-4 \mathrm{~m}^{3}$ wastewater per ton of PTA generated [5]. Significant part of PTA wastewater consists of $p$-toluic acid ( $p$-Tol), benzoic acid (BA), 4-carboxybenzaldehyde (4-CBA), phthalic acid (PA) and terephthalic acid (TA) with minor concentrations of 4-formylbenzoic acid, methyl acetate and $p$ xylene [6-8]. At times, the contribution of these chemicals towards COD can be more than $75 \%$ in the wastewater. With increasing PET consumption, the treatment of PTA wastewater and contaminated environments is very essential to preserve natural ecosystems and protect the environment because untreated PTA waste water released into the environment is toxic to living organisms [9-12]. Acute toxicity, sub-acute toxicity, chronic toxicity and molecular toxicity have been reported for exposure to pure chemical PTA [11,13-16].

Additionally, phthalate, its ester and degradation intermediates are suspected to cause cancer and renal damage, and as a result of this, the US Environmental Protection Agency has recently added this class of chemicals to the list of priority pollutants [17]. The toxic concentrations or doses of the pure chemical PTA were as high as over $1000 \mathrm{mg} \cdot \mathrm{L}^{-1}$. Several methods such as, advanced oxidation processes (AOP), supercritical water oxidation, UV-assisted ozonation $\left(\mathrm{UV} / \mathrm{O}_{3}\right)$, ozone assisted photochemical oxidation $\left(\mathrm{UV} / \mathrm{O}_{3} / \mathrm{H}_{2} \mathrm{O}_{2}\right)$, photo-fenton oxidation $\left(\mathrm{UV} / \mathrm{H}_{2} \mathrm{O}_{2} / \mathrm{FeSO}_{4}\right)$, ozone-assisted pho- 
to-fenton oxidation $\left(\mathrm{UV} / \mathrm{O}_{3} / \mathrm{H}_{2} \mathrm{O}_{2} / \mathrm{FeSO}_{4}\right)$ and radiation treatment using gamma-ray have been used for the treatment of PTA wastewater [18-21]. However, cost for treatment and generation of toxic intermediates and sludge, which in turn cause secondary pollution, have been identified as major limitations of these methods. To overcome these limitations, biodegradation technology has been proposed and used.

Biodegradation or biological treatment has been found to be environmental friendly and cost effective and in some cases, energy-efficient compared to chemical processes. However in biodegradation, poor degradation of the intermediate poses a problem [22-24]. Nevertheless, this problem does not pose serious hindrance to the application of biodegradation to wastewater treatment. Regarding the application of biodegradation technology for PTA wastewater treatment, activated sludge process (aerobic treatment) has been proposed and used [23]. Advantages of aerobic treatment are high purification efficiency $(>90 \%)$, high process stability and rapid biodegradability of all compounds. Meanwhile, in recent years, anaerobic treatment has been preferred to conventional aerobic activated sludge treatment process due to the reasons presented in Table 1.

In light of this, the objective of this paper is to present a critical comparison between aerobic and anaerobic degradation of PTA wastewater with a view to furnishing the readers with useful information on PTA wastewater treatment and provoking their thought toward the application of the process to wastewater treatment from similar industrial settings. Furthermore, the comparison is presented through the diagnosis of a scenario which concerns a PTA wastewater containing terephthalate, benzoate and acetate. The concentrations of the terephthalate, benzoate and acetate in the waste stream are 3 ,

Table 1. Comparison between aerobic activated sludge and anaerobic degradation of wastewater.

\begin{tabular}{|c|c|}
\hline Aerobic activated sludge & Anaerobic degradation \\
\hline High energy intensive & Low energy intensive \\
\hline Large volume of sludge & Small volume of sludge \\
\hline $\begin{array}{l}\text { Requires highly skilled } \\
\text { operation and process control }\end{array}$ & $\begin{array}{l}\text { Requires moderate skilled } \\
\text { operation and process control }\end{array}$ \\
\hline Additional nutrients is required & No additional nutrients required \\
\hline Costly technical specifications & No costly technical specifications \\
\hline Poor solid settleability & Good solid settleabiblity \\
\hline $\begin{array}{l}\text { Requires high hydraulic } \\
\text { retention time (HRT) }\end{array}$ & Low HRT \\
\hline Low elimination rate & High elimination rate \\
\hline
\end{tabular}

2 and $2 \mathrm{~g} \cdot \mathrm{L}^{-1}$, respectively. The wastewater leaves the plant at a temperature of $54^{\circ} \mathrm{C}-60^{\circ} \mathrm{C}$ and a $\mathrm{pH}$ of 5 . Thus this paper compares mesophilic and thermophilic anaerobic degradation of the wastewater and suggests an economically viable option for the treatment of the wastewater. In the course of the diagnosis, issues like bioavailability, biodegradability, microbial population, kinetics and thermodynamics of anaerobic degradation of PTA wastewater were considered and discussed.

\section{BIOAVAILABILITY, BIODEGRADABILITY AND TOXICITY OF TA}

Terephthalic acid is a benzene ring structure with two carboxylic acid groups. These two acid groups are responsible for the high solubility of TA in water. It is known that TA has a high solubility of about $140 \mathrm{~g} \cdot \mathrm{L}^{-1}$ at $\mathrm{pH}>5.5$ [25]. Therefore, bioavailability of TA for the degrading bacteria is promising. However, the $\mathrm{pH}$ should be $>5.5$ or else precipitation of TA might occur. When the $\mathrm{pH}<5.5$, TA precipitation occurs, and the TA will be unavailable anymore for degradation. Kleerebezem et al. [26] have proposed a two-step biodegradation pathway for PTA wastewater. In this pathway, the first step involves the decarboxylation of TA to form benzoate and the second step involves the transformation of benzoate to carboxycyclohexane. The two carboxylic acid groups have a stabilizing effect on the benzene ring and make it, therefore, not easy to degrade. In term of toxicity, TA has not been found to be severely toxic to methanogens at the usual concentration of TA present in PTA wastewater $[4,27,28]$. Also, the partition coefficient $\left(\log k_{O W}\right)$ of TA has been reported to be 1.16 to 2.00 (depending on which isomer of TA and of the state of the isomer-dissociated or non-dissociated) [28].

\section{THERMODYNAMICS OF ANAEROBIC DEGRADATION OF PTA WASTEWATER}

The main conversion reactions that occur during anaerobic treatment of PTA wastewater are TA decarboxylation, benzoate oxidation, benzoate reduction, and/or carbocyclohexane oxidation. Under the prevalent conditions $(\mathrm{pH}$, concentrations and temperature of the wastewater), the TA decarboxylation can proceed but close to the biological limit of $-20 \mathrm{KJ} \cdot \mathrm{mol}^{-1}$. The benzoate oxidation, however, does not proceed under these conditions. The only reaction that is probably promoted is the TA carboxylation (but only for a limited time; until the benzoate concentrations reached a high value). The benzoate reduction proceeds because $\mathrm{H}_{2}$ that is needed for the reaction must come from the benzoate oxidation, 
which cannot proceed under these conditions. At $\mathrm{pH}$ of 7 , however, all the reactions can proceed except the carbocyclohexane reaction.

Furthermore, the TA decarboxylation reaction might not proceed, because when the TA decarboxylation and benzoate reduction and oxidation are carried out by the same organism, benzoate reduction and oxidation pathway is favoured. This occurs because those two reactions deliver more energy than the TA decarboxylation. Figure 1 and Figure 2 depict the different Gibbs free energies for the reactions at the actual concentrations of $\mathrm{TA}$, benzoate and acetate at different $\mathrm{pH}, 37^{\circ} \mathrm{C}$ and $55^{\circ} \mathrm{C}$, respectively (The values of Gibbs free energy of formation of the compounds were taken from Reference [26] and Reference [29]). Therefore, to remove the TA, the benzoate and acetate concentrations should be low. Comparing Figure 1 and Figure 2 shows that an increase in temperature from $37^{\circ} \mathrm{C}$ to $55^{\circ} \mathrm{C}$ improves the energy yield for almost all reactions except the benzoate reduction (see Figure 2). This indicates that higher temperatures are preferable for TA degradation. However,

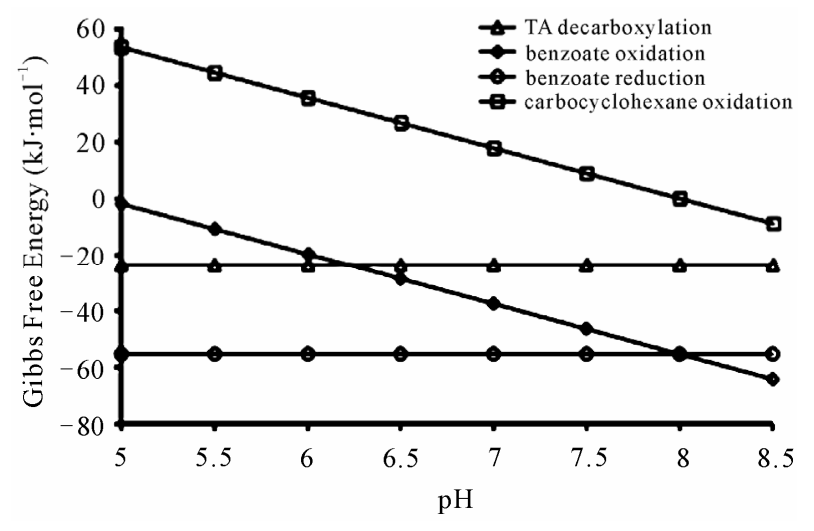

Figure 1. Gibbs free energy for the different reactions at different $\mathrm{pH}$ at the actual concentrations of TA, Benzoate and acetate at $37^{\circ} \mathrm{C}$.

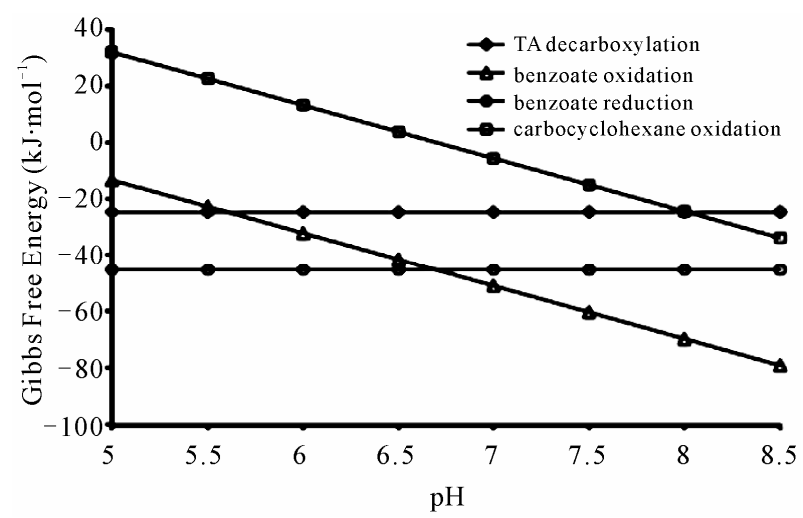

Figure 2. Gibbs free energy for the different reactions at different $\mathrm{pHs}$ at the actual concentrations of TA, benzoate and acetate at $55^{\circ} \mathrm{C}$.
Kleerebezem and Lettinga [30] reported unsuccessful results on anaerobic degradation PTA wastewater at thermophilic condition. The failure could be attributed to the possibility of low number of thermophilic anaerobic TA degrading microorganisms in the inoculum's sludge and/or non-optimal operating conditions during the TA degradation. In the contrary, Chen et al. [31] reported relatively high TA and benzoate removal in one reactor at thermophilic condition compared to the removal at mesophilic condition ( 0.7 versus $0.5 \mathrm{~g} \mathrm{TA} / \mathrm{gVSS}$ (day) $)^{-1}$ ). Success of Chen et al. could be attributed to the different TA biodegradation kinetics during thermophilic condition compared to the kinetics during mesophilic condition.

At higher temperatures, Gibbs free energies for TA biodegradation are more negative. Thus favouring and enhancing thermophilic PTA degradation. At the same time, the $\mathrm{pH}$ should be taken into consideration. Considering the influence of $\mathrm{pH}$, plots on Figures $\mathbf{1}$ and $\mathbf{2}$ are only valid for a $\mathrm{pH} \geq 5.5$ because at $\mathrm{pH}<5.5$, TA is mainly available in solid form [4]. Also, optimal growth of the TA degrading organisms occurs in a range of $\mathrm{pH} 6$ to 7 [4]. Therefore for feasible anaerobic degradation of the PTA wastewater described in this study (the wastewater has a $\mathrm{pH}=5$ ), the $\mathrm{pH}$ of the wastewater should be increased to 6 or 7 by adding alkali. In the optimal $\mathrm{pH}$ growth range, the benzoate oxidation and reduction gain more energy than the TA decarboxylation. Also, it is likely that only TA decarboxylation will proceed if the benzoate concentration is low as suggested by Kleerebezem et al. [26]. The hypothesis of Kleerebezem et al. [26] was verified in this study through computations. Based on these computations, we concluded that anaerobic degradation of the wastewater (our case study) is possible and feasible under both mesophilic and thermophilic conditions. However, in a case where the $\mathrm{pH}$ of the wastewater $\leq 5$, during the treatment the $\mathrm{pH}$ of the sludge should be increased to 7 (the optimum $\mathrm{pH}$ for the anaerobic treatment [30]). Addition of appropriate amount of chemicals such as sodium hydroxide solution $(\mathrm{NaOH})$ sodium bicarbonate $\left(\mathrm{NaHCO}_{3}\right)$ to the wastewater bioreactor could raise the $\mathrm{pH}$ to 7 .

\section{MICROBIAL POPULATION FOR ANAEROBIC DEGRADATION OF PTA WASTEWATER}

Identification of structure and diversity of a microbial community is important in degradation processes because it is useful for better understanding of the physiological roles of different species in degradation processes. Different types of bacteria have different roles under different conditions. Like in thermophilic and mesophilic conditions, microbial community that will be 
involved in anaerobic degradation of PTA wastewater will definitely exhibit different roles at those conditions. For mesophilic condition, a temperature range of $35^{\circ} \mathrm{C}$ $37^{\circ} \mathrm{C}$ is necessary while for thermophilic degradation, temperature of about $55^{\circ} \mathrm{C}$ is essential [32]. In the case study under consideration in this paper, the PTA wastewater is generated at $54^{\circ} \mathrm{C}-60^{\circ} \mathrm{C}$, therefore, thermophilic treatment is preferable.

In addition, through the application of thermophilic treatment, the use of cooling units required to cool the PTA wastewater from $60^{\circ} \mathrm{C}$ to $37^{\circ} \mathrm{C}$, which require additional costs, could be avoided. According to van Lier et al. [33], thermophilic methanogenic consortia have, often, a higher specific organic removal rate than the mesophilic consortia. However, it is difficult, but important to get the thermophilic organisms in the original inoculum and to provide the required conditions for thermophilic degradation [31]. Under mesophilic condition, $\delta$-Proteobacteria and the subcluster Ih of the group "Desulfotomaculum lineage I" [34] have been identified as the microorganisms responsible for the PTA wastewater degradation under mesophilic condition. In addition, the syntrophic methanogenic counterparts identified as $\mathrm{Me}$ thanosaeta concilii and members of Methanospirillum and Methanobacteriaceae are the microorganisms which play a role in the degradation process.

Some methods like Restriction Fragment Length Polymorphism (RFLP), Clone libraries and Fluorescence InSitu Hybridization (FISH) and Scanning Electron Microscopy (SEM) analysis are used to identify microbial population and diversity in anaerobic degradation of PTA wastewater during thermophilic condition. According to results from a SEM analysis, six different dominant morphotypes have been identified to play significant roles in degradation process of PTA wastewater under thermophilic anaerobic degradation condition [31]. According to the authors, the dominant cells, the fat rods, are responsible for TA degradation in the reactor. The second most dominant cells, the bamboo-shaped cells, and rods with flat ends (Methanosaeta-like species) are methanogens that utilize acetate.

In clone library analysis, according to the investigation on phylotype. Methanothrix thermophila in the acetoclastic Methanosaeta group is found as the dominant phylotypes. The remaining clones are related to mainly hydrogen-utilizing Methanospirillum species [35]. The Desulfotomaculum group is found to be the most dominant that include diverse isolates and clone sequences from various thermophilic and mesophilic environments [36]. The desulfotomaculum group is also identified as a dominant group according to the results of RFLP technique [31].

The FISH results with rRNA-targeted probes were used to identify the domains Archaea (ARC915) and Bacteria (EUB338_I/II/III). According to the results of Loy et al. [37], the Desulfotomaculum group was identified as a dominant group with probe DFMI227a. Under a microscopic examination, the authors observed that these groups referred to the fat rods, are probably responsible for TA degradation under thermophilic conditions. Another new probe TA55_OP5 was used to identify a different population. This probe hybridized to very small rod shape cells, which have the second largest fraction in the sludge. As a result of all methods used to analyze the microbial community, the microbial diversity for thermophilic degradation can be specified as Methanothrix thermophila-related methanogens, Desulfotomaculum-related bacterial populations in the Gram-positive low-G $+\mathrm{C}$ group and OP5-related populations, which are responsible for degradation of terephthalate.

\section{KINETICS OF PTA WASTEWATER DEGRADATION AND REACTOR DESIGN}

Kinetics of the system is essential to determining the volume and hydraulic retention time (HRT) of the reactor in both mesophilic and thermophilic conditions. In order to study the kinetics of degradation, in many cases, some assumptions are made due to insufficient data from literature. To justify and validate these assumptions, experiments are carried out to obtain the kinetic parameters. In the scenario presented in this paper, loading rate of about $10 \mathrm{~kg} \mathrm{COD} \mathrm{m}{ }^{-3} \cdot \mathrm{day}^{-1}$ [26] for mesophilic condition and $16 \mathrm{~kg} \mathrm{COD} \mathrm{m}^{-3} \cdot$ day $^{-1}$ [31] for thermophilic condition were assumed for the reactor. For mesophilic and thermophilic conditions, the solid (sludge) retention time (SRT) was assumed to be 40 days based on the reports presented in Reference [26] and Reference [31]. The authors also reported hydraulic retention time (HRT) of 5 to $8 \mathrm{~h}$ in their studies. The operating conditions adap- ted in the computation of HRT, the reactor volume and the chemical oxygen demand (COD) content per $\mathrm{m}^{3}$ wastewater for the scenario presented in this study are presented in Table 2. The HRT obtained was obtained using Eq.1:

$$
H R T=V / Q
$$

where $H R T$ is the hydraulic retention time $(\mathrm{h}) ; V$, the bioreactor volume in $\mathrm{m}^{3}$ and $\mathrm{Q}$, the flow rate in $\mathrm{m}^{3} \cdot \mathrm{h}^{-1}$. The computed HRT was between 15 and $24 \mathrm{~h}$. This value is higher than HRT reported in Reference [26] and Reference [31] despite using the same SRT. The discrepancy can be attributed to the assumptions made in this study. Furthermore, it has been understood that the SRT could be high because of the low growth rate of the 
Table 2. Data used for bioreactor design.

\begin{tabular}{ccc}
\hline $\begin{array}{c}\text { Wastewater } \\
\text { characteristic }\end{array}$ & $\begin{array}{c}\text { Thermophilic } \\
\text { condition }\end{array}$ & $\begin{array}{c}\text { Mesophilic } \\
\text { condition }\end{array}$ \\
\hline COD $\left(\mathrm{kg} \mathrm{COD} \mathrm{m}^{-3}\right)$ & 10.25 & 10.25 \\
$\begin{array}{c}\text { Maximum loading rate } \\
\left(\mathrm{kg} \mathrm{COD} \mathrm{m}^{-3} \cdot \mathrm{day}^{-1}\right)\end{array}$ & 16 & 10 \\
$\begin{array}{c}\text { Solid Retention Time } \\
\text { (SRT), day }\end{array}$ & 40 & 40 \\
\hline
\end{tabular}

PTA degrading bacteria. Therefore, based on the computed SRT, volume of bioreactor required for the degradation was calculated.

The value obtained for the COD was $10.4 \mathrm{~kg} \mathrm{COD} \mathrm{m}^{-3}$. By considering different effluent flow rates from the production plant, the total loading rate, in $\mathrm{kg} \mathrm{COD/day,}$ was computed. By dividing the flow rate with the maximal loading rate gives the minimum reactor volume required for the PTA wastewater degradation. For mesophilic condition, the minimum reactor volume required is ca. $1 \mathrm{~m}^{3}$ per $1 \mathrm{~m}^{3}$ wastewater flow per day and for thermophilic condition, ca. $0.6 \mathrm{~m}^{3}$ reactor volume per 1 $\mathrm{m}^{3}$ wastewater flow per day is required. Although, the reactor volume required for PTA wastewater degradation depends on the wastewater flow rate from the production plant. Having considered this, attempt was made to compute reactor volume at different wastewater flow rates for both mesophilic and thermophilic conditions. Figure 3 depicts the reactor volume as a function of the flow rate. From the reactor volume, the HRT was computed using Eq.1. Minimum HRT of $24.6 \mathrm{~h}$ and $15.4 \mathrm{~h}$ were obtained for mesophilic condition and thermophilic condition, respectively:

As it can be seen in Figure 3, smaller reactor volume is required for thermophilic anaerobic degradation compared to mesophilic anaerobic degradation to treat the same volume of PTA wastewater. This finding is corroborated by the studies of Kleerbezem et al. [26] and Chen et al. [31] where it has been shown experimentally that the TA conversion rate is higher in the thermophilic compared to mesophilic.

\section{CONCLUSIONS AND FUTURE OUTLOOK}

Processes involved in the anaerobic treatment of TA wastewater have been discussed from the perspective a case study. A good choice to treat the PTA wastewater, as presented in this case study, is through thermophilic anaerobic degradation reactor. To degrade the amount of the PTA wastewater, one-stage anaerobic reactor will be required for thermophilic condition while at mesophilic condition degradation two-stage reactor is required. However in both cases, and as suggested by Noyola et al.

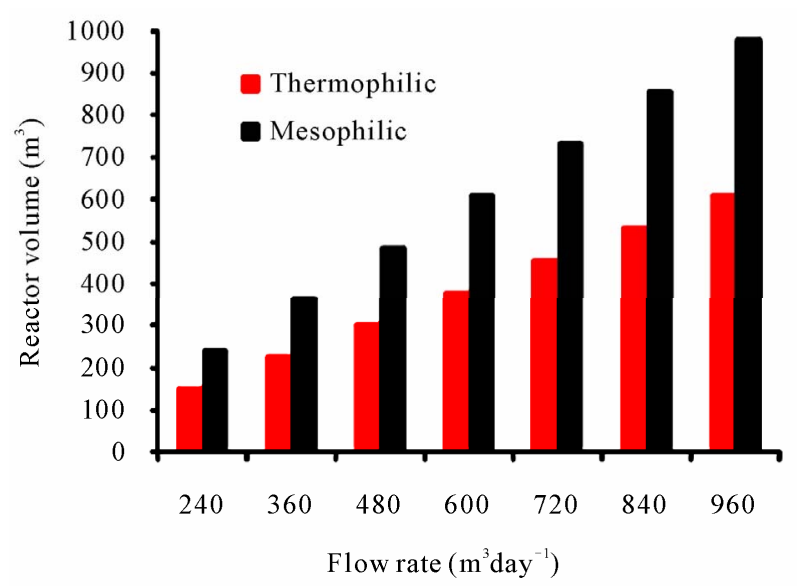

Figure 3. Reactor volume as a function of flow rate.

[38], anaerobic degradation alone could not accomplish effective PTA wastewater treatment because the suspended solids in the raw wastewater could cause clogging and accumulation of toxicity in the reactor [39]. Therefore, it is expected that post-treatment with an aerobic unit could ensure the effluent quality below the international waste disposal benchmark. However, a big fluctuation in the removal efficiency of the reactor also could pose a problem [31].

Thermophilic condition is preferable to mesophilic condition, because with a one-stage reactor at thermophilic condition, the same removal rate can be achieved as with a two-stage reactor at mesophilic condition. The costs for a two-stage reactor are much higher than for a one-stage process, so one-stage will be preferable. Also, for the fact that the PTA wastewater stream exists at a temperature of $54^{\circ} \mathrm{C}-60^{\circ} \mathrm{C}$, cooling units will be required to reduce the temperature before mesophilic degradation is feasible. This eventually translates into additional cost for the treatment of the PTA wastewater. But in thermophilic degradation, no cooling unit is required. Moreover, in both cases, the $\mathrm{pH}$ of the wastewater should be raised to $6-7$ by adding alkali because the microbial degrading kinetics is at optimum at this condition.

Regarding the future perspective of anaerobic biodegradation of PTA wastewater, in-depth investigation of anaerobic degradation mechanism and bio-kinetics is essential. Although, Farjdo et al. [27] reported an investigation on anaerobic degradation mechanism and biokinetics using upflow anaerobic sludge blanket (UASB) reactor for easily biodegradable compounds, viz., acetic, benzoic and formic acids from PTA wastewater, however, more research efforts are still needed, especially, for PTA wastewater treatment. As suggested by Karthik et al. [1], pretreatment of PTA wastewater with coagulation-flocculation prior to biodegradation is techno-economically 
viable for the treatment of non-biodegradable PTA waste water. Thus, more research efforts are required on the optimization of this process when coupled with anaerobic treatment. Additionally, stable and effective reactors are required.

In the 1970's, Lettinga and his co-workers at Wageningen University in The Netherlands developed upflow anaerobic sludge blanket (UASB) reactor for anaerobic degradation of wastewater. A schematic of a typical UASB reactor is presented in Figure 4. Some research efforts also have been carried out with the use of biofilm reactors with attached growth medium for microbes [22,26,31]. Furthermore, in the laboratory, different experimental set-ups have been proposed and used for experimentations. Figure 5 depicts the down flow tubular fixed film reactor proposed and used by Noyola et al. [38] for PTA wastewater treatment. The experimental set-up was made with plexiglass column of $1 \mathrm{~m}$ high and $96 \mathrm{~mm}$ internal diameter and packed with 21 polyvinyl chloride (PVC) tubes of each, $670 \mathrm{~mm}$ high and $12.7 \mathrm{~mm}$ diameter. In total, the reactor could provide $1.05 \mathrm{~m}^{2}$ support area and a void volume of $4.75 \mathrm{~L}$. According to Noyola et al. [38], compared to UASB reactors, downflow tubular fixed-film reactor has good resistance to shock loads and periods without feeding, major limitations in anaerobic treatment of PTA wastewater.

In the same vein, Pophali et al. [40] proposed and used a laboratory scale upflow anaerobic fixed-film fixed-bed reactor (AFFFBR) (see Figure 6) to investigate PTA wastewater treatment. The reactor was made of glass with reactor volume $2.43 \mathrm{~L}$. Also, about $1.45 \mathrm{~L}$ of the total volume of the reactor was occupied with $10-20 \mathrm{~mm}$ (size) stones resulting in void volume 0.98 .

Major problems in the anaerobic treatment of PTA wastewater have been identified to be chemical inhibition effects and shock loads [38]. To overcome these limitations, expanded-bed granular activated carbon (GAC) anaerobic reactors have been developed and implemented to investigate the treatment of PTA-containing waste water [41-44]. Figure 7 depicts a typical example of an expanded-bed granular activated carbon (GAC) anaerobic reactor. Going by the studies of Tsuno and Kawamura [41], the reactor can be made of a thick Plexiglas tube with a diameter of $100 \mathrm{~mm}$, occupying $10 \mathrm{~L}$ volume. $1.5 \mathrm{~kg}$ GAC with a particle size of $0.9-1.1 \mathrm{~mm}$ is placed in the reactor as the attached growth medium. The liquid in the reactor can be circulated from the top part to the bottom to expand the GAC medium by $25 \%$, resulting in an expanded-bed volume of $4.3 \mathrm{~L}$. The concept behind the mechanism of the reactor is based on the physical and biological removal mechanisms. In the physical removal mechanism, adsorption of inhibitory chemicals is by adsorption onto GAC while the biological removal is

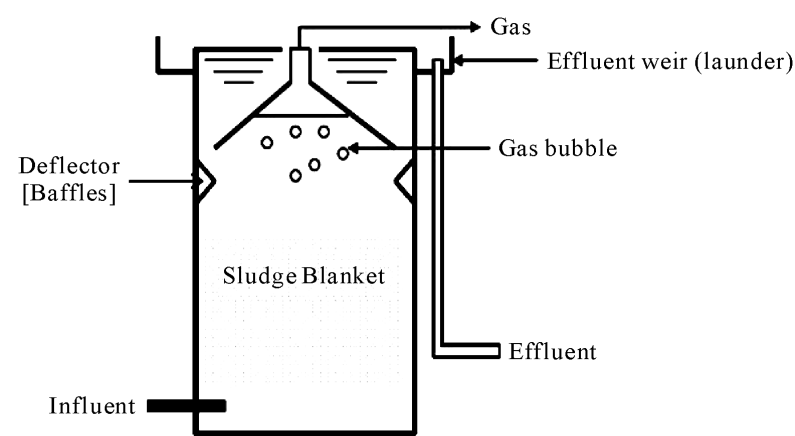

Figure 4. Upflow anaerobic sludge blanket (UASB) reactor.

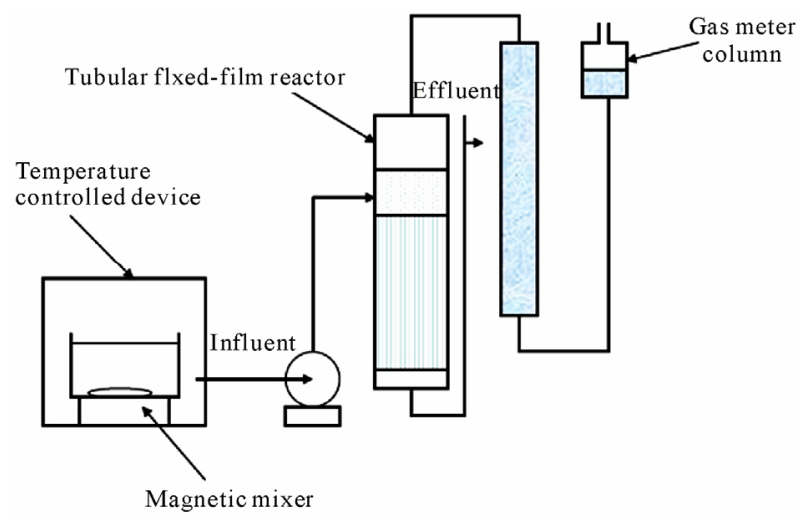

Figure 5. Downflow tubular fixed-film reactor (Adapted from Reference [38]).

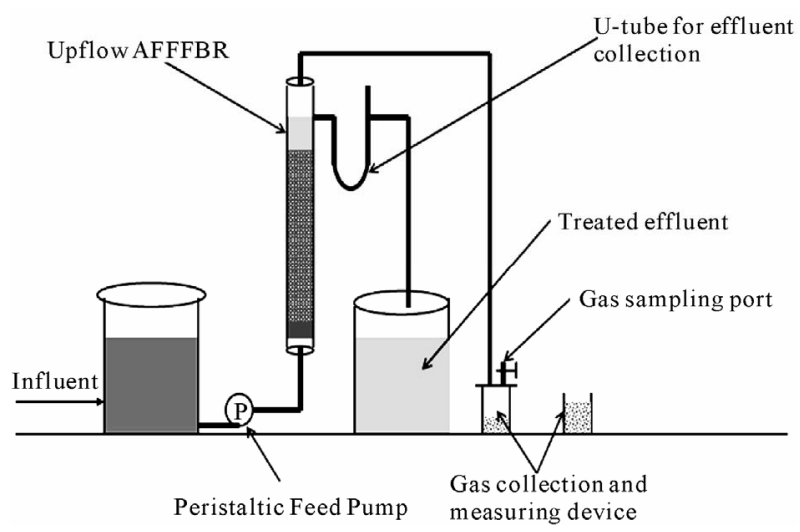

Figure 6. Upflow anaerobic-aerobic fixed-film fixed-bed reactor (UAFFFBR) (Adapted from Reference [40]).

through degradation by microorganisms growing on the GAC. Through the adsorptive function of the GAC, effect of the inhibitory chemicals and effect of shock loads are minimized. Despite series of reactors that have been proposed and developed, there is still need for further research efforts toward optimizing and up-scaling of these reactors for anaerobic treatment of PTA wastewater. Therefore, it is expected that the scenario presented in this paper will be thought provoking, especially, for chemical/process engineers, environmental engineers, 


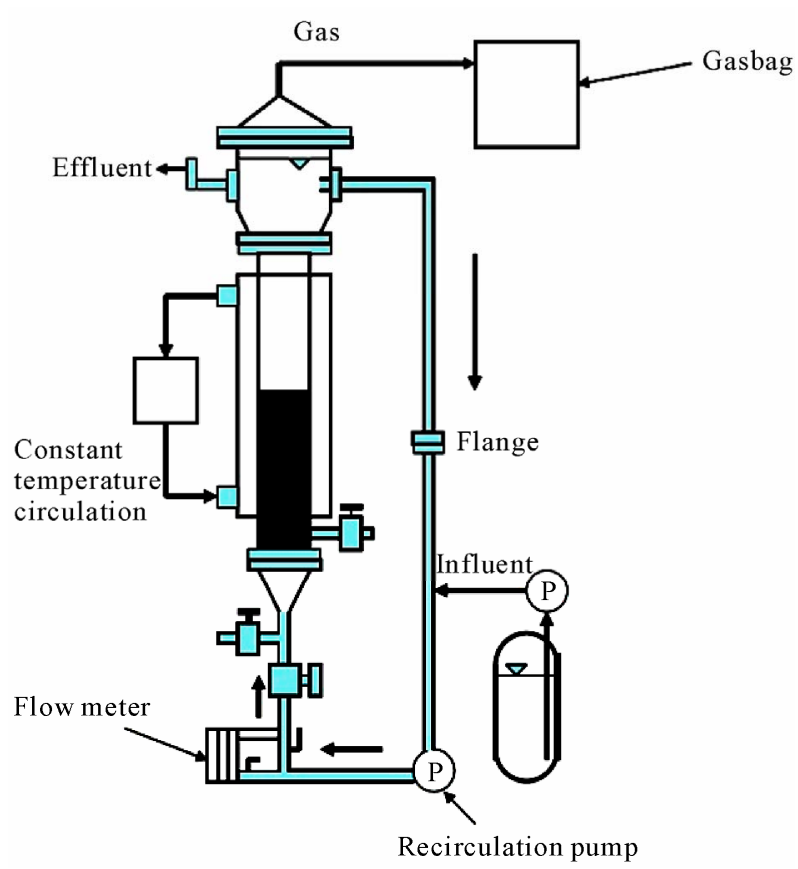

Figure 7. An expanded-bed granular activated carbon (GAC) anaerobic reactors (Adapted from Reference [41]).

scientists and other professionals in environmental management, particularly in the area of industrial wastewater treatment. In addition, application of the process diagnosed in this paper is possible in the treatment of other petrochemical wastewater such as, phenol-containing wastewater, benzene/benzoic acid-containing wastewater or wastewater from other similar industrial settings.

\section{ACKNOWLEDGEMENTS}

MOD is grateful to the authority of Obafemi Awolowo University, Nigeria, for study leave to carry out this study.

\section{REFERENCES}

[1] Karthik, M., Dafale, N., Pathe, P. and Nandy, T. (2008) Biodegradability enhancement of purified terephthalic acid wastewater by coagulation-flocculation process as pretreatment. Journal of Hazardous Materials, 154, 721-730. doi:10.1016/j.jhazmat.2007.10.085

[2] Chinese Pure Terephthalic Acid Market Report (2007) http://studio-5.financialcontent.com/financialvisions?Cha nnelID $=3191 \&$ GUID $=3460172 \&$ Page $=$ MediaViewer 2008

[3] Franck, H.G. and Stadelhofer, J.W. (1988) $p$-Xylene and its derivates: Terephthalic acid. In: Franck, H.G. Ed., Industrial Aromatic Chemistry: Raw Materials, Process Products, Springer-Verlag, Berlin, 283-290.

[4] Kleerbezem, R., Mortier, J., Hulshoff Pol, L.W. and Lettinga, G. (1997) Anaerobic pretreatment of petrochemical effluents: Terephthalic acid wastewater. Water Science and Technology, 36, 237-248.

doi:10.1016/S0273-1223(97)00393-4

[5] Macarie, H. and Guyot, J.P. (1992) Inhibition of the me- thanogenic fermentation of ptoluic acid (4-methyl-benzoic acid) by acetate. Applied Microbiology and Biotechnology, 38, 398-402. doi:10.1007/BF00170093

[6] Liangming, X., Yuxiang, C. and Xiangdong, Z. (1991) The anaerobic biological treatment of high strength petrochemical wastewater by a hybrid reactor. International Conference on Petroleum Refining and Petrochemical Processing, Beijing, 11-15 September 1991, 120-126.

[7] Kleerebezem, R., Hulshoff Pol, L.W. and Lettinga, G. (1999) Anaerobic biodegradability of phthalic acid isomers and related compounds. Biodegradation, 10, 63-73. doi:10.1023/A:1008321015498

[8] Kleerebezem, R., Hulshoff Pol, L.W. and Lettinga, G. (1999) Anaerobic degradation of phthalate isomers by methanogenic consortia. Applied Microbiology and Biotechnology, 65, 1152-1160.

[9] Wolkowski, T.R., Chin, T.Y. and Heck, H. (1982) Chemical urolithiasis 3: Pharmacokinetics and transplacental transport of terephthalic acid in Fischer-344 rats. Drug Metabolism and Disposition, 10, 486-490.

[10] Pernille, E., Kristian, K., Brandt, A., Rasmussen, L.H., Ovesen, R.G. and Sørensen, J. (2007) Microbial degradation and impact of Bracken toxin ptaquiloside on microbial communities in soil. Chemosphere, 67, 202-209. doi:10.1016/j.chemosphere.2006.08.025

[11] Qi, S.T., Wang, X.R. and Xu, X.K. (2002) Study on the bladder calculi and bladder cancer induced by terephthalic acid in rats. Journal of hygiene research, 31, 10-12.

[12] Scholz, N. (2003) Ecotoxicity and biodegradation of phthalate monoesters. Chemosphere, 53, 921-926. doi:10.1016/S0045-6535(03)00668-4

[13] Chen, B.J., Yuan, Y.X. and Qu, K.M. (2000) Joint effects of acetaldehyde, $p$-phthalic acid and ethylene glycol on growth of Tetradesmus wiseconsinense. Journal of Fishery Sciences of China, 7, 82-85.

[14] Qu, K.M., Yuan, Y.X. and Chen, M.S. (2000) Acute toxicity and join effect of pollutants in fiber wastewater in Daphnia magna. Journal of Fishery Sciences of China, 7, 78-81.

[15] Chen, B.J., Yuan, Y.X. and Wang, H.P. (2001) Joint effects of acetaldehyde, $p$-phthalic acid and ethylene glycol on growth of silver carp and grass carp. Journal of Fishery Sciences of China, 8, 73-76.

[16] Zhang, H.D., Xu, X.K. and Gong, N. (2001) Study on the toxicity of terephthalic acid to NIH3T3 cells. Chinese Journal of Industrial Medicine, 14, 65-67.

[17] US Environmental Protection Agency (2007) Federal Register. http://www.deq.state.va.us/vpdes/pdf/BactiFinalRule.pdf

[18] Deng, Y., Zhang, K., Chen, H., Wu, T., Krzyaniak, M., Wellons, A., Bolla, D., Douglas, K. and Zuo, Y. (2006) Iron-catalyzed photochemical transformation of benzoic acid in atmospheric liquids: Product identification and reaction mechanisms. Atmospheric Environment, 40, 36653676. doi:10.1016/j.atmosenv.2006.03.019

[19] Chan, A.H., Chan, C.K., Barford, J.P. and Porter, J.F. (2003) Solar photocatalytic thin film cascade reactor for treatment of benzoic acid containing wastewater. Water Research, 37, 1125-1135. doi:10.1016/S0043-1354(02)00465-7

[20] Brillas, E., Cabot, P.L., Rodriguez, R.M., Arias, C., Garrido, J.A. and Oliver, R. (2004) Degradation of the herbi- 
cide 2, 4-DP by catalyzed ozonation using the $\mathrm{O} 3 / \mathrm{Fe} 2+/$ UVA system. Applied Catalysis, 51, 117-127. doi:10.1016/j.apcatb.2004.02.007

[21] Radoiu, M.T., Martin, D.I., Calinescu, I. and Iovu, H. (2004) Preparation of polyelectrolytes for wastewater treatment. Journal of Hazardous Materials, 106, 27-37. doi:10.1016/j.jhazmat.2003.08.014

[22] Kleerbezem, R., Beckers, J., Hulshoff Pol, L.W. and Lettinga, G. (2005) High rate treatment of terephthalic acid production wastewater in a two stage anaerobic bioreactor. Biotechnology and Bioengineering, 91, 169-179. doi:10.1002/bit.20502

[23] Lau, C.M., (1978) Staging aeration for high efficiency treatment of aromatic acids plant wastewater. Proceedings of 32nd Independent Wastewater Conference, West Lafayette, 10 May 1977, 63-74.

[24] Macarie, H. and Guyot, J.P. (1995) Use of ferrous sulphate to reduce the redox-potential and allow the start-up of UASB-reactors treating slowly biodegradable compounds: Application to a wastewater containing 4-methylbenzoic acid. Environmental Technology, 16, 1185-1192. doi:10.1080/09593331608616354

[25] Macarie, H., Noyola, A. and Guyot, J.P. (1992) Anaerobic treatment of a petrochemical wastewater from a terephthalic acid plant. Water Science and Technology, 25, 223-235.

[26] Kleerebezem, R., Pol, L.W.H. and Lettinga, G. (1999) Energetic of product formation during anaerobic degradation of phthalate isomers and benzoate. FEMS Microbiology Ecology, 29, 273-282. doi:10.1111/j.1574-6941.1999.tb00618.x

[27] Fajardo, C., Guyot, J.P., Macarie, H. and Monroy, O. (1997) Inhibition of anaerobic digestion by terephthalic acid and its aromatic byproducts. Water Science and Technology, 36, 83-90. doi:10.1016/S0273-1223(97)00510-6

[28] OECD SIDS (2001) Terephthalic acid. UNEP publications, Nairobi.

[29] Amend, J.P. and Shock, E.L. (2001) Energetics of overall metabolic reactions of thermophilic and hyperthermophilic Archaea and Bacteria. FEMS Microbiology Reviews, 25, 175-243. doi:10.1111/j.1574-6976.2001.tb00576.x

[30] Kleerebezem, R. and Lettinga, G. (2000) High-rate anaerobic treatment of purified terephthalic acid wastewater. Water Science and Technology, 42, 259-268.

[31] Chen, C.-L., Macarie, H., Ramirez, I., Olmos, A., Ong, S.L., Monroy, O. and Liu, W.T. (2004) Microbial community structure in a thermophilic anaerobic hybrid reactor degrading terephthalate. Microbiology, 150, 3429-3440. doi:10.1099/mic.0.27193-0

[32] Macarie, H. (2000) Overview of the application of anaerobic treatment to chemical and petrochemical wastewaters. Water Science and Technology, 42, 201-214.
[33] Van Lier, J.B., Rebac, S. and Lettinga, G. (1997) Highate anaerobic wastewater treatment under psychrophilic and thermphilic conditions. Water Science and Technology, 35, 199-206. doi:10.1016/S0273-1223(97)00202-3

[34] Qiu, Y.L., Sekiguchi, Y., Imachi, H., Kamagata, Y., Tseng, I.C., Ohashi, S.S. and Harada, H. (2004) Identification and isolation of anaerobic, syntrophic phthalate isomer-degrading microbes from methanogenic sludges treating wastewater from terephthalate manufacturing. $A p$ plied Microbiology and Biotechnology, 70, 1617-1626.

[35] Wu, J.H., Liu, W.T., Tseng, I.C. and Cheng, S.S. (2001) Characterization of microbial consortia in an anaerobic granular sludge system treating terephthalate. Microbiology, 147, 373-382.

[36] Castro, H.F., Williams, N.H. and Ogram, A. (2000) Phylogeny of sulphate-reducing bacteria. FEMS Microbiology Ecology, 31, 1-9.

[37] Loy, A., Lehner, A., Lee, N., Adamczyk, J., Meier, H., Ernst, J., Schleifer, K.H. and Wagner, M. (2002) Oligonucleotide microarray for $16 \mathrm{~S}$ rRNA gene-based detection of all recognized lineages of sulfate-reducing prokaryotes in the environment. Applied and Environmental Microbiology, 68, 5064-5081. doi:10.1128/AEM.68.10.5064-5081.2002

[38] Noyola, A., Macarie, H. and Guyot, J.P. (1990) Treatment of TA plant wastewater with an anaerobic fixed film reactor. Environmental Technology, 11, 239-248. doi:10.1080/09593339009384862

[39] Guyot, J.P., Macarie, H. and Noyola, A. (1990) Anaerobic digestion of a petrochemical wastewater using the UASB process. Applied Biochemistry and Biotechnology, 24/25, 579-589. doi:10.1007/BF02920280

[40] Pophali, G.R., Khan, R., Dhodapkar, R.S., Nandy, T. and Devotta, S. (2007) Anaerobic-aerobic treatment of PTA effluent: A techno-economic alternative to two-stage aerobic process. Journal of Environmental Management, 85, 1024-1033. doi:10.1016/j.jenvman.2006.11.016

[41] Tsuno, H. and Kawamura, M. (2009) Development of an expanded-bed GAC reactor for anaerobic treatment of terephthalate - containing wastewater. Water Research, 43, 417-422. doi:10.1016/j.watres.2008.10.046

[42] Suidan, M.T., Strubler, C.E., Kao, S.W. and Pfeffer, J.T. (1983) Treatment of coal gasification wastewater with anaerobic filter technology. Journal of Environmental Management, 55, 1263-1270.

[43] Tsuno, H., Kawamura, M. and Somiya, I. (1996) Anaerobic degradation of pentachlorophenol (PCP) in biological expanded-bed reactor. Water Science and Technology, 34, 335-344. doi:10.1016/0273-1223(96)00663-4

[44] Tsuno, H., Kawamura, M. and Oya, T. (2006) Application of biological activated carbon anaerobic reactor for treatment of hazardous chemicals. Water Science and Technology, 53, 251-260. doi:10.2166/wst.2006.360 